\title{
Dual-Band Circular Microstrip Patch Antenna Based on Reactively Loaded Dual Frequency Technique And DGS for RFID Reader
}

\author{
Nanang Ismail ${ }^{1}$, Elita Wijayanti ${ }^{2}$, Folin Oktafiani ${ }^{3}$, Abdul Latip ${ }^{4}$ \\ \{nanang.is@uinsgd.ac.id ${ }^{1}$,wijayantielita@gmail.com,oktafiani@gail.com, abdullatip1110@gmail.com\} \\ Electrical Engineering Department, UIN Sunan Gunung Djati Bandung ${ }^{1,2,4}$, \\ Research Center for Electronic and Telecommunication Indonesian Institute of Sciences ${ }^{3}$
}

\begin{abstract}
One of the superior wireless technologies in the identification of various objects that are efficient, fast, cheap, and effective, especially in the field of logistics, namely technology of Radio Frequency Identification (RFID). Differences in the working frequency of RFID technology used for logistics needs can be overcome by designing a reader antenna that has two working frequencies (dual-band). This paper proposes a dualband microstrip antenna design with patch circular for RFID readers. The method used to generate two working frequencies is the Reactively Loaded Dual Frequency method, which is to load the antenna in the form of two slots and one stub on the patch circular. Besides, the antenna is also designed with the addition of the Defected Ground Structure (DGS) in the form of a rectangular slot to improve the S-parameters. The antenna is realized using a substrate made from FR-4 with a thickness of $1.6 \mathrm{~mm}$, the dielectric constant is 4.3 , and uses a coaxial probe type. The measurement results prove that the microstrip antenna is capable of producing two working frequencies namely $2.48 \mathrm{GHz}$ and $5.768 \mathrm{GHz}$ which are by following the standards of ISO 18000-4 and ISO 18000-5. At a frequency of $2.48 \mathrm{GHz}$, the values of $\mathrm{S}_{11}$ is $-11.453 \mathrm{~dB}$, VSWR 1.741 , and bidirectional radiation patterns were obtained. At a frequency of $5.768 \mathrm{GHz}$, values of $\mathrm{S} 11$ is $-11,490$ $\mathrm{dB}$, VSWR 1,728 and bidirectional radiation patterns were obtained. VSWR resulting from the measurement shows the results that meet the mirostrip antenna criteria, which is $\leq 2$. The $S_{11}$ produced is in accordance with the specifications, with a value of $\leq-10 \mathrm{~dB}$.
\end{abstract}

Keywords: Microstrip Antenna, Dual-band, Patch Circular, Reactively Loaded Dual Frequency, DGS, RFID.

\section{Introduction}

Wireless communication requires high mobility [1] so that to support this the microstrip antenna can be used which has the characteristics of small and light size, a neat structure, affordable price, and easy to be integrated with other components [2]. One of the applications of wireless communication is Radio Frequency Identification (RFID). The technology of RFID can do many things in the identification of various objects, can be used to identify the operation of any distribution system so that it is efficient, fast, cheap, and effective, especially in logistics. Various agencies and companies in Indonesia have used electronic identification [1]. Microstrip antenna for RFID reader has been developed with a variety of methods and various work frequencies [3] [4]. 
The regulation of RFID work frequency allocation in each country is different. The allocation of the frequency of RFID work in Indonesia is issued by the Director General of Post and Telecommunications of the Ministry of Communication and Information which refers to the International Standards Organization (ISO). The frequency allocation for RFID is in the range of $923 \mathrm{MHz}-925 \mathrm{MHz}$ [1] [5]. Table 1 shows the standard allocation of RFID working frequency in Indonesia.

Table 1. Frequency Allocation of RFID in Indonesia

\begin{tabular}{|c|c|c|}
\hline Standard & Frequency & Application \\
\hline ISO 11784 & & Animal Identification (read only) \\
\hline ISO $14223 / 1$ & $125 \mathrm{kHz} / 135 \mathrm{kHz}$ & Animal Identification (read/write) \\
\hline ISO $18000-2$ & & Logistics \\
\hline ISO 10536 (ID1 format) & 0 to $30 \mathrm{MHz}$ & High security \\
\hline ISO 14443 & & $\begin{array}{l}\text { Proximity cards (contactless } \\
\text { controller) }\end{array}$ \\
\hline ISO 15693 & & Vicinity cards (contactless \\
\hline ISO $18000-3$ & $13.56 \mathrm{MHz}$ & $\begin{array}{l}\text { memory) } \\
\text { Logistics }\end{array}$ \\
\hline EPC Class I RF & & Electronic product code \\
\hline NFC ECMA 340 & & $\begin{array}{l}\text { Mobile near-field communications } \\
\text { (smartcard payment) }\end{array}$ \\
\hline ISO $18000-7$ & $433 \mathrm{MHz}$ & Logistics \\
\hline ISO $18000-6$ & & Logistics \\
\hline EPC Class I Gen 2 & 860 to $960 \mathrm{MHz}$ & $\begin{array}{l}\text { Electronic product code (reading of } \\
\text { multiple tags) }\end{array}$ \\
\hline ISO 18000-4 & $\begin{array}{l}2.4 \text { to } 2.4835 \mathrm{GHz}, \\
2.45 \mathrm{GHz}\end{array}$ & Logistics \\
\hline ISO $18000-5$ & 5.725 to $5.875 \mathrm{GHz}$ & Logistics \\
\hline
\end{tabular}

Various antenna development for the application of UHF RFID reader has been developed, starting from near field antenna [6] [7] [8] to far-field antenna [9]. Based on Table 1, there are several RFID working frequencies for logistics applications. The use of one antenna for one application is not profitable. So there are various techniques for making dual-band or multiband antenna. Various research and development of dual-band antenna have been widely done with the aim of antenna efficiency because if one antenna only covers one frequency band, the amount becomes inefficient. The dual-band antenna is discussed in that can work at frequency 2.3 and 3.5 GHz. Other dual-band antennas for RFID readers are discussed in paper, where antennas are made for Portable RFID Readers. One technique for generating more than one working frequency on an antenna is to use the Reactively Loaded Dual Frequency technique, which is by adding a load to the antenna. Loads can be in the form of stubs, slots, pins, and others.

Based on the above explanation, this paper discusses the proposed dual-band microstrip antenna design for RFID applications with patch circular that work on two frequencies in the range of $2.4-2.4835 \mathrm{GHz}$ (ISO 18000-4) and 5.725 - 5.875 GHz (ISO 18000-5). The antenna was developed with the Reactively Loaded Dual Frequency technique for generating dualfrequency. Improved antenna performance is done by adding a Defected Ground System (DGS). 
DGS is one way to suppress surface waves which will indirectly affect the performance of an antenna. DGS technique is done by etching the groundplane area, one of them by adding rectangular slots [2].

\section{Proposed Antenna Design}

The antenna is designed to meet the specifications as listed in Table 2.

Table 2. Targeted antenna specifications

\begin{tabular}{ll}
\hline \multicolumn{1}{c}{ Parameter } & \multicolumn{1}{c}{ Specifications } \\
\hline Frequency & Dual-band in the range 2.4-2.4835 \\
& GHz (ISO 18000-4) and 5.725- \\
& $5.875 \mathrm{GHz}$ (ISO 18000-5) \\
Substrate type & FR-4 \\
Thickness of the substrate $(h)$ & $1,6 \mathrm{~mm}$ \\
Permettivity $\left(\varepsilon_{r}\right)$ & 4.3 \\
S11 & $\leq-10 \mathrm{~dB}$ \\
VSWR & $\leq 2$ \\
\hline
\end{tabular}

The antenna is designed in two stages, namely the antenna design stage of single-band, and the antenna design stage of dual-band with the Method of Reactively Loaded Dual Frequency. At each stage, characterization is carried out to obtain results that are by following the targeted specifications

\subsection{Stage I: Design of a Single-Band Antenna}

The design begins with the determination of the initial dimensions through theoretical calculations. The parameters calculated are the dimensions of the patch, the feed channel, the dimensions of the groundplane, and the dimensions of the substrate. The results of the calculations are made into the initial design of a single-band antenna with the antenna specifications listed in Table 3.

Table 3. Initial dimensions of a single-band antenna

\begin{tabular}{ll}
\hline \multicolumn{1}{c}{ Parameter } & \multicolumn{1}{c}{ Specification } \\
\hline Speed light reference & $3 \times 10^{8} \mathrm{~m} / \mathrm{s}$ \\
The radius of the patch (r) & $17.26 \mathrm{~mm}$ \\
Minimum dimensions of the & $38.3 \times 32.2 \mathrm{~mm}$ \\
groundplane & \\
$\begin{array}{l}\text { Dimensions of the substrate } \\
\text { Dimension of the feed line }\end{array}$ & $38.3 \times 32.2 \mathrm{~mm}$ \\
\hline
\end{tabular}


The calculation refers to the $2.4 \mathrm{GHz}$ frequency value, the speed of light $3 \times 10^{8} \mathrm{~m} / \mathrm{s}$, FR4 substrate with a thickness of $1.6 \mathrm{~mm}$, and permittivity $\left(\varepsilon_{r}\right)$ which is 4.3 .

The simulation results show that the value does not meet the target specifications, so the characterization of the size of the circular patch radius affects the frequency shift and changes in the value of $S_{11}$. Table 4 shows the results of the characterization of the size of the patch radius.

Table 4. Characterization of circular patch for single-band antenna

\begin{tabular}{cccc}
\hline No & $\mathrm{r}(\mathrm{mm})$ & $\mathrm{Fr}(\mathrm{GHz})$ & $\mathrm{S} 11(\mathrm{~dB})$ \\
\hline 1 & 17.26 & 2.294 & -8.0791 \\
2 & 16.76 & 2.358 & -9.9925 \\
3 & 16.26 & 2.429 & -9.8189 \\
4 & 16.50 & 2.407 & -11.362 \\
\hline
\end{tabular}

In Table 4, characterization is performed for each radius reduction $\Delta \mathrm{r}=0.5 \mathrm{~mm}$. The $3^{\text {rd }}$ characterization produces frequencies that exceed $2.4 \mathrm{GHz}$ so that at the $4^{\text {th }}$ characterization, the radius is raised again $16.50 \mathrm{~mm}$ and produces $f_{r}=2.407 \mathrm{GHz}$ and $\mathrm{S}_{11}$ is $-11.362 \mathrm{~dB}$. Figure 1 is a stage I design of a single-band antenna for working frequencies in the range $2.4-2.4835 \mathrm{GHz}$.

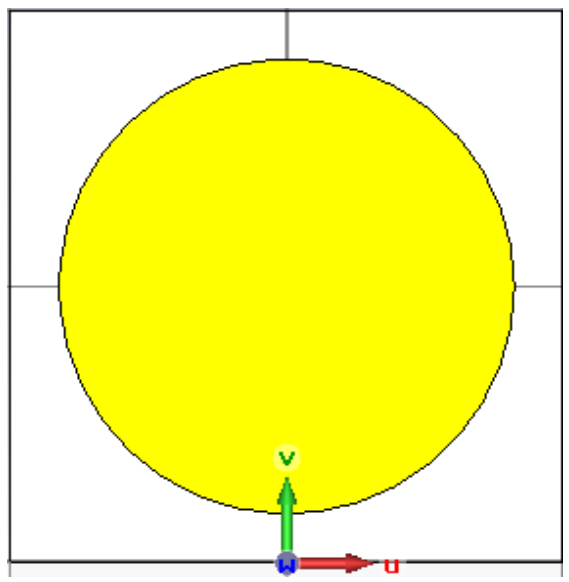

a).

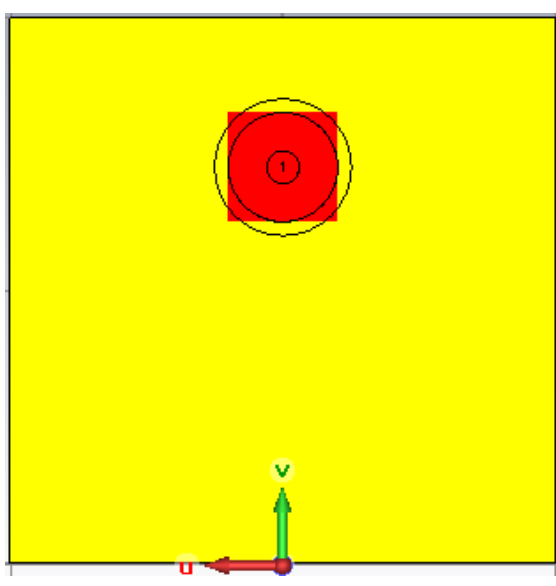

b).

Figure 1. Stage I: design of a single-band antenna, a). front view, b). back view

Table 1. Comparison of Reliability of SUTTE, SMA, dan MACD

\begin{tabular}{lll}
\hline Indicator & MSE & MAD \\
\hline SUTTE & 1.385 & 0.832 \\
SMA & 2.590 & 1.090 \\
MACD & 14.670 & 2.952 \\
\hline
\end{tabular}




\subsection{Stage II: Design of the Dual-Band Antenna}

After obtaining the first working frequency, the next stage is the antenna design for the second working frequency. The method used to generate two working frequencies is Reactively Loaded Dual Frequency, namely by adding a load of 2 slots and 1 stub to the patch circular. Besides, the groundplane section is then added with DGS in the form of a rectangular slot. Characterization was carried out on the dimensions of the patch, dimensions of the groundplane, dimensions of the slots, dimensions of the stub, and dimensions of DGS until the results were obtained according to the targeted specifications. Figure 2 shows the final design of a dual-band antenna for RFID readers, while Table 5 shows the dimensions of each parameter.

P sub

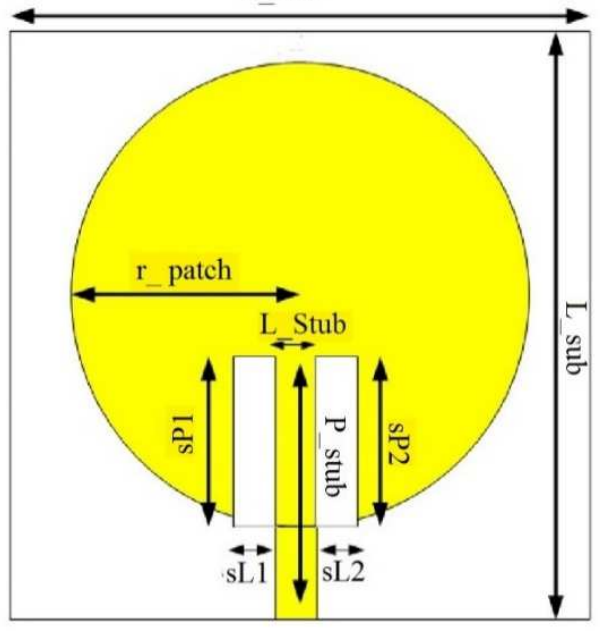

a).

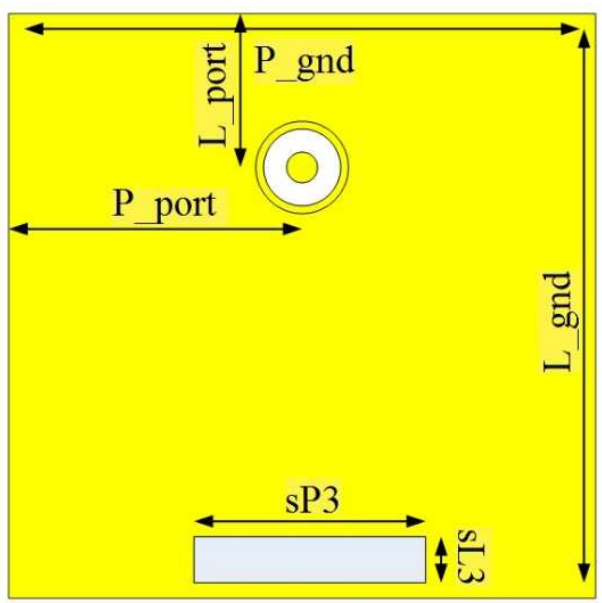

b).

Figure 2. Final design of a dual-band antenna: a). front view, b). back view

Table 5. Final dimensions of dual-band antenna

\begin{tabular}{cllc}
\hline No & \multicolumn{1}{c}{ Parameter } & Symbol & $\begin{array}{c}\text { Dimension } \\
(\mathrm{mm})\end{array}$ \\
\hline 1 & Length of groundplane & P_gnd & 40 \\
2 & Width of grounplane & L_gnd & 40 \\
3 & Length of substrate & P_sub & 40 \\
4 & Width of substrate & L_sub & 40 \\
5 & Length of the 1 $1^{\text {st }}$ slot & sP1 & 10 \\
6 & Width of the $1^{\text {st }}$ slot & sL1 & 1 \\
7 & Length of the 2 ${ }^{\text {nd }}$ slot & sP2 & 10 \\
9 & Width of the 2 $2^{\text {nd }}$ Slot & sL2 & 1 \\
10 & Length of the stub & P_stub & 8.285 \\
11 & Width of stub & L_stub & 3.1
\end{tabular}




\begin{tabular}{lllc}
12 & Length of the $3^{\text {rd }}$ slot & sP3 & 20 \\
13 & Width of the $3^{\text {rd }}$ slot & sL3 & 5 \\
14 & Radius of patch & r_patch & 14.35 \\
15 & $\begin{array}{l}\text { Vertical distance of the } \\
\text { feed line }\end{array}$ & L_port & 10 \\
16 & $\begin{array}{l}\text { Horizaontal distance of } \\
\text { the feed line }\end{array}$ & P_port & 15 \\
\hline
\end{tabular}

Based on the simulation, the design shown in Figure 2 and Table 5, gives results that are on target. The antenna works at the RFID working frequency according to the target, namely $2.48 \mathrm{GHz}$ with S11 of-27.832 dB and a frequency of $5.768 \mathrm{GHz}$ with $\mathrm{S} 11$ of $-43.203 \mathrm{~dB}$. VSWR obtained at the time of simulation for a working frequency of $2.48 \mathrm{GHz}$ was 1.1596 and at a frequency of $5.768 \mathrm{GHz}$, the VSWR value was 1.0068 .

\section{Results and Analysis}

The antenna is realized using FR-4 substrate with a thickness of $h=1,6 \mathrm{~mm}$ and permittivity $\varepsilon_{r}=4.3$. The antenna realization results can be seen in Figure 3 .

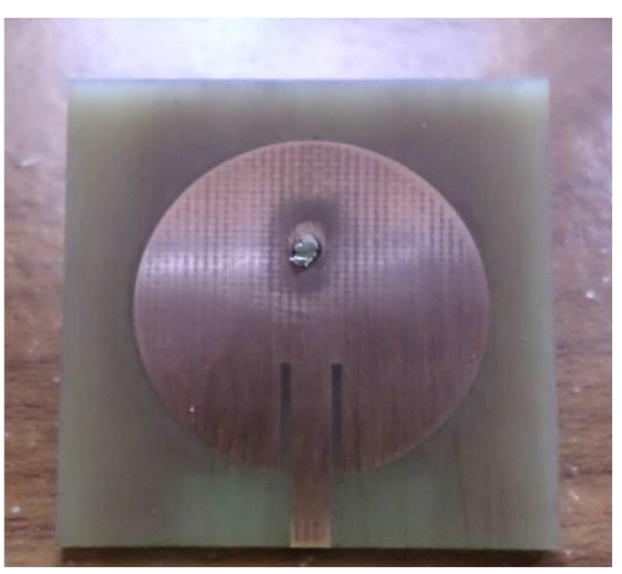

a).

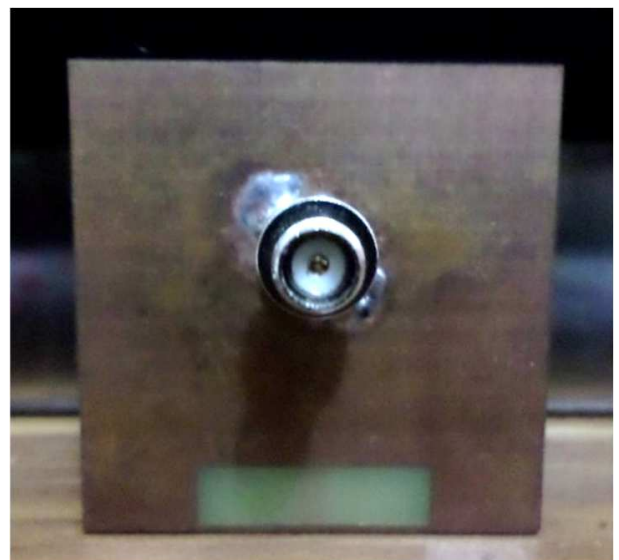

b).

Figure 3. The antenna realization: a). front view, b). back view

Measurements are made in two ways: single port and multiple port measurements. Single port measurement is performed to determine the parameters $\mathrm{S}_{11}$, VSWR, bandwidth, and the input impedance of the antenna. Double port measurement is made to determine the polarization and antenna radiation pattern. But in this paper, the discussion is focused on parameters S11, VSWR, polarization, and radiation patterns. The single and double port measurement scheme respectively are shown in Figure 4 and Figure 5. 


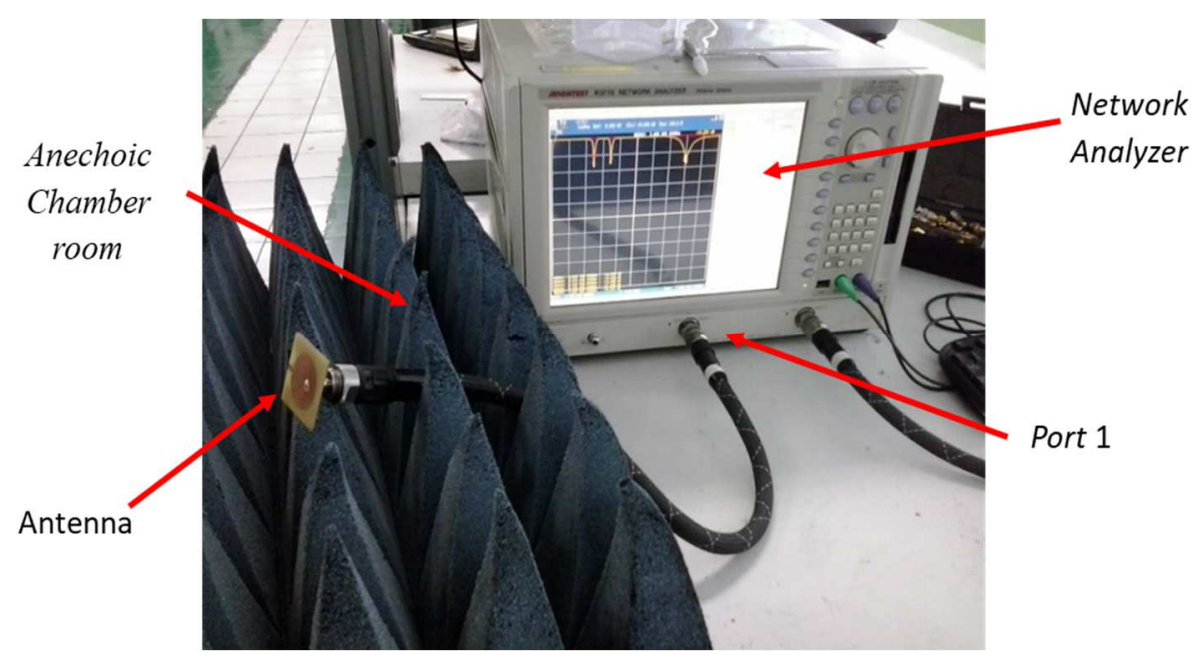

Figure 4. Single port measurement scheme

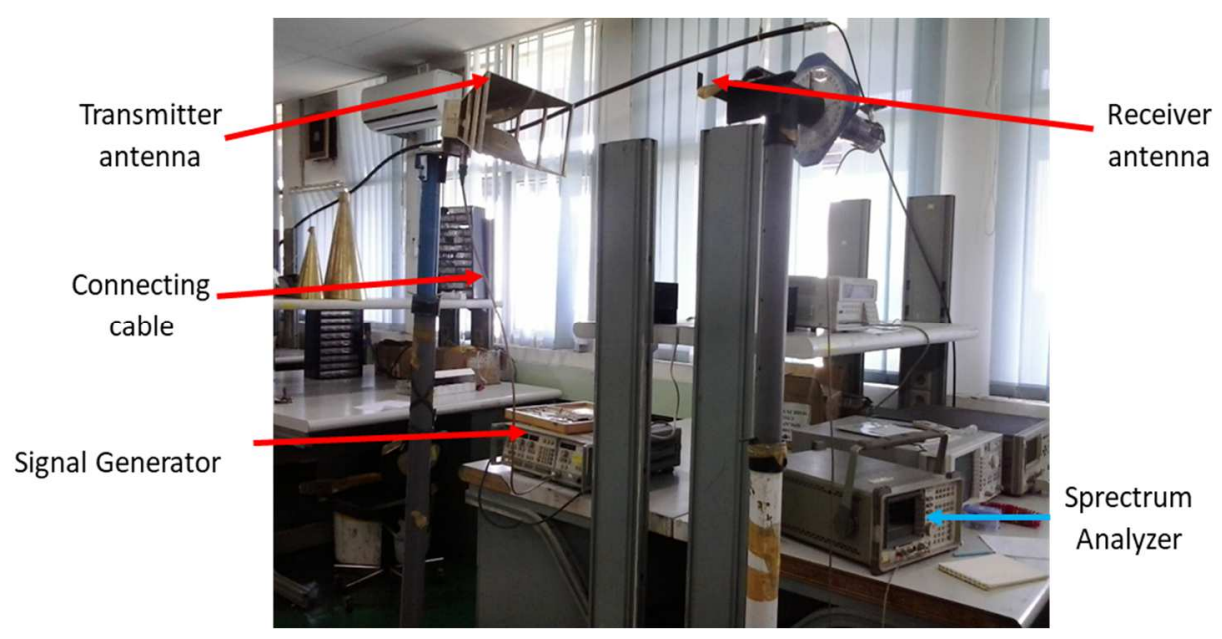

Figure 5. Multiple port measurement Scheme

Based on the measurement results at $2.48 \mathrm{GHz}$ frequency, $\mathrm{S} 11$ of $-11.453 \mathrm{~dB}$ is obtained and at $5.768 \mathrm{GHz}$ frequency, $\mathrm{S} 11$ of $-11.490 \mathrm{~dB}$ is obtained. Graphically, the $\mathrm{S} 11$ parameter can be seen in Figure 6. 


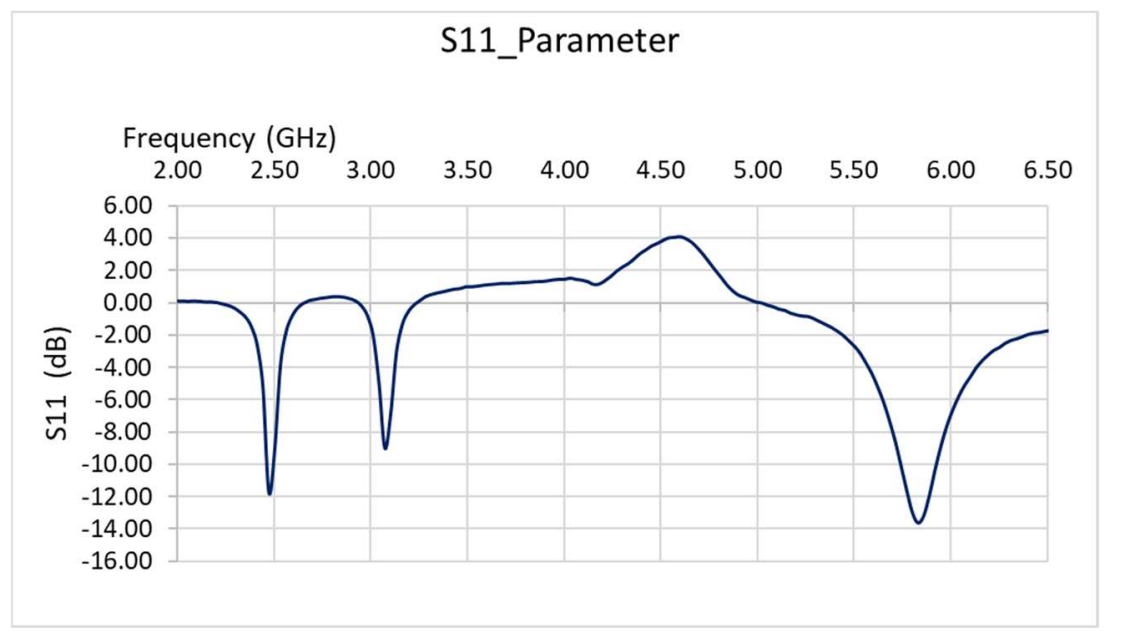

Figure 6. S11 of the dual-band antenna

Meanwhile, at a frequency of $2.48 \mathrm{GHz}$, a VSWR 1.741 is generated and a frequency of $5.748 \mathrm{GHz}$ is generated at a VSWR 1.728. VSWR generated by both working frequencies has fulfilled the microstrip antenna criteria, namely $\leq 2$. Graphically, VSWR can be seen in Figure 7.

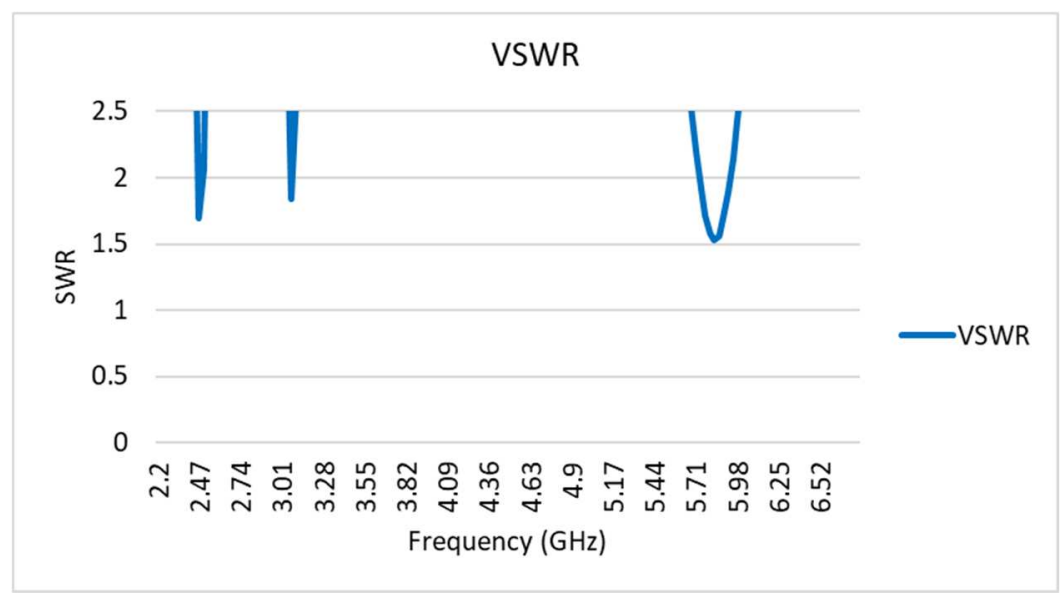

Figure 7. Grafik VSWR antena dual-band

Based on the results of multiple port measurements, at a frequency of $2.48 \mathrm{GHz}$, azimuth field radiation patterns are generated at an angle of $0^{\circ}$ by $-21.97 \mathrm{dBm}$ while the radiation pattern of the elevation field at an angle of $90^{\circ}$ is $-45.89 \mathrm{dBm}$. At a frequency of $5.768 \mathrm{GHz}$ the azimuth field radiation pattern is produced at an angle of $0^{\circ}$ by $-43.07 \mathrm{dBm}$ while the radiation pattern of the elevation field at an angle of $90^{\circ}$ is $-45.95 \mathrm{dBm}$. Radiation patterns at the frequencies of $2.48 \mathrm{GHz}$ and $5.678 \mathrm{GHz}$ produced the type of bidirectional radiation pattern leading to angles of $0^{\circ}$ and $190^{\circ}$. At $2.48 \mathrm{GHz}$ frequency, polarization at $0^{\circ}$ angle is $-21.97 \mathrm{dBm}$ while at 5.768 
$\mathrm{GHz}$ frequency polarization is generated at an angle of $0^{\circ}-42.07 \mathrm{dBm}$. The second frequency polarization is in the form of imperfect linear polarization (ellipse). Radiation and polarization patterns at each work frequency can be seen in Figure 8, Figure 9, Figure 10, and Figure 11.

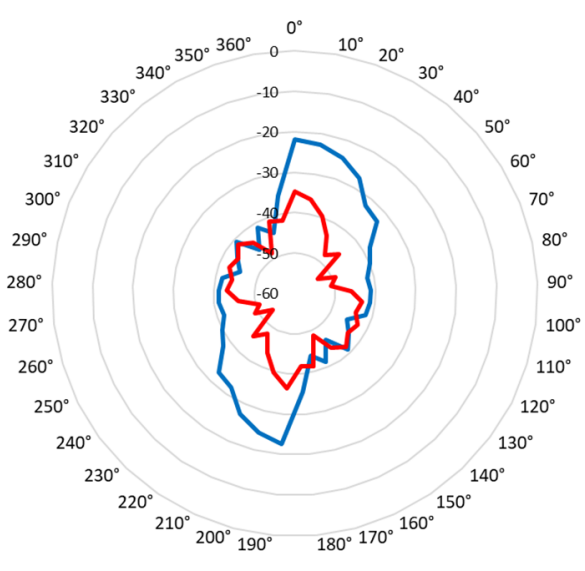

-Azimuth (dBm) -Elevation (dBm)

Figure 8. Antenna radtiation pattern at the $2.48 \mathrm{GHz}$ frequency

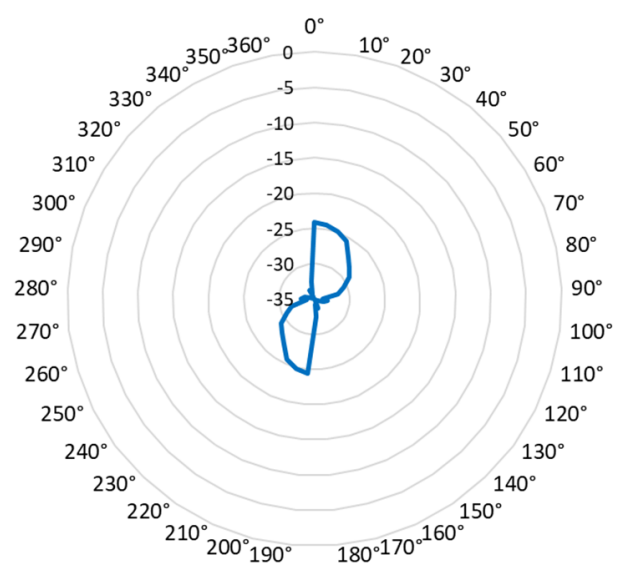

Figure 10. Antenna polarization at the 2.48 $\mathrm{GHz}$ frequency

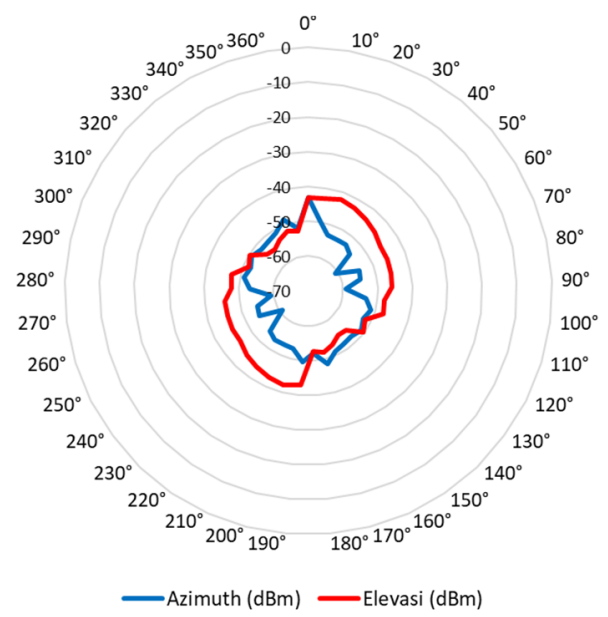

Figure 9. Antenna radiation pattern at the $5.768 \mathrm{GHz}$ frequency

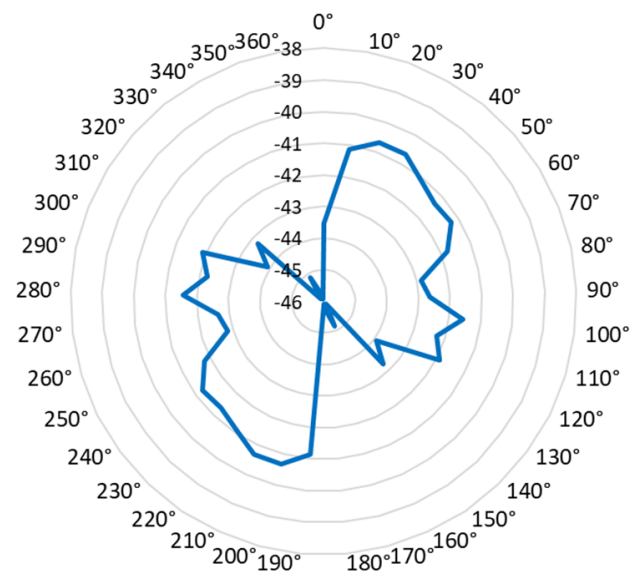

Fig 11. Antenna radiation pattern at the $5.768 \mathrm{GHz}$ frequency 


\section{Conclusions}

The Reactively Loaded Dual Frequency method used successfully generated two working frequencies on the designed antenna. The measurement results prove that the microstrip antenna as an RFID reader is able to produce two working frequencies (dual-band) namely $2.48 \mathrm{GHz}$ and $5.768 \mathrm{GHz}$ which are by following the standards of ISO 18000-4 and ISO 18000-5.

\section{Acknowledgments}

On this occasion, we present our gratitude to the Faculty of Science and Technology UIN Sunan Gunung Djati, which provides the facility for research, and to the Research and Publishing Centre of UIN SGD Bandung for support to this activity.

\section{References}

[1] "CHAINWAY - Handheld Computer_Handheld RFID Reader_Handheld Terminal." [Online]. Available: https://www.chainway.net/?gclid=CjwKCAiA6vXwBRBKEiwAYE7iS_27XnrF3Dka AO5qi21ZELqAqfpTRFc_t5eG8_8jxTy772YTHju4yhoCbtsQAvD_BwE. [Accessed: 15-Jan-2020].

[2] "N. Ismail, T. S. Gunawan, S. K. Sari, T. Praludi and E. A. Hamidi, 'Design of microstrip hairpin bandpass filter for $2.9 \mathrm{GHz}-3.1 \mathrm{GHz}$ s-band radar with defected ground structure,' Malaysian Journal of Fundamental and Applied Sciences, vol. 14, no. 4, pp. 448-455, 2018. - Penelusuran Google." [Online]. Available:

https://www.google.com/search?q=N.+Ismail\%2C+T.+S.+Gunawan $\% 2 \mathrm{C}+\mathrm{S} .+\mathrm{K} .+$ Sari $\% 2 \mathrm{C}+\mathrm{T} .+$ Praludi+and + E. + A. + Hamidi $\% 2 \mathrm{C}+\% 22 \mathrm{Design}+$ of + microstrip + hairpin + band pass + filter + for $+2.9+\mathrm{GHz}+-+3.1+\mathrm{GHz}+\mathrm{s}-$

band + radar+with + defected + ground + structure $\% 2 \mathrm{C} \% 22+$ Malaysian + Journal + of + Fund amental+and + Applied + Sciences $\% 2 \mathrm{C}+$ vol. $+14 \% 2 \mathrm{C}+$ no. $+4 \% 2 \mathrm{C}+$ pp. $+448-$

$455 \% 2 \mathrm{C}+2018 . \& \mathrm{rlz}=1 \mathrm{C} 1 \mathrm{CHBD}$ idID878ID878\&oq $=\mathrm{N} .+$ Ismail $\% 2 \mathrm{C}+\mathrm{T} .+\mathrm{S} .+$ Gunawa $\mathrm{n} \% 2 \mathrm{C}+\mathrm{S} .+\mathrm{K} .+$ Sari $\% 2 \mathrm{C}+\mathrm{T} .+$ Praludi + and + E. + A. + Hamidi $\% 2 \mathrm{C}+\% 22 \mathrm{Design}+\mathrm{of}+$ micro strip+hairpin+bandpass + filter + for $+2.9+\mathrm{GHz}+-+3.1+\mathrm{GHz}+\mathrm{s}-$

band + radar + with + defected + ground + structure $\% 2 \mathrm{C} \% 22+$ Malaysian + Journal + of + Fund amental+and + Applied + Sciences $\% 2 \mathrm{C}+$ vol. $+14 \% 2 \mathrm{C}+$ no. $+4 \% 2 \mathrm{C}+$ pp. $+448-$

$455 \% 2 \mathrm{C}+2018 . \& \mathrm{aqs}=$ chrome..69i57.462j0j4\&sourceid $=$ chrome\&ie $=\mathrm{UTF}-8$. [Accessed: 15-Jan-2020].

[3] C. S. Nair and M. Shah, External quality audit: has it improved quality assurance in universities? .

[4] S. Chen, X. Yang, and H. Sun, "Circularly polarized stacked circular microstrip antenna with an arc feeding network," in Lecture Notes in Electrical Engineering, 2011, vol. 98 LNEE, no. VOL. 2, pp. 927-932, doi: 10.1007/978-3-642-21765-4_115.

[5] "Regulation of Frequency and Standardization - SDPPI Regulation - Direktorat Jenderal Sumber Daya dan Perangkat Pos dan Informatika." [Online]. Available: https://www.postel.go.id/?mod=main\&cid=3\&page_id=93\&lang=en. [Accessed: 15- 
Jan-2020].

[6] "[IEEE 2012 IEEE International Conference on RFID-Technologies and Applications (RFID-TA) - Nice, France (2012.11.5-2012.11.7)] 2012 IEEE International Conference on RFID-Technologies and Applications (RFID-TA) - Use of transmission lines as near field antenna in UHF RFID." [Online]. Available: https://dokumen.tips/documents/ieee-2012-ieee-international-conference-on-rfidtechnologies-and-applications-58ccb394786ea.html. [Accessed: 15-Jan-2020].

[7] “Active Rfid Tags,uhf Rfid Reader Manufacturers | Marktraceiot.com.” [Online]. Available:

https://www.marktraceiot.com/?gclid=CjwKCAiA6vXwBRBKEiwAYE7iS3ISoZNR w9rLtnO7DTs7ayMVRKGjUgBDfKFzEv6T7_35meUpLfFsVBoCPXEQAvD_BwE. [Accessed: 15-Jan-2020].

[8] M. Al-Gabri, C. LI, and L. Li, "Improving ZigBee AODV Mesh Routing Algorithm Topology and simulation analysis," TELKOMNIKA Indones. J. Electr. Eng., vol. 12, no. 2, Feb. 2014, doi: 10.11591/telkomnika.v12i2.3576.

[9] "RFID Tags - RFID Tags Application, RFID Tracking System, Best rfid tag Manufacturer in india." [Online]. Available:

http://www.omniatags.com/?gclid=CjwKCAiA6vXwBRBKEiwAYE7iS2dlzqypGggw LZq9uB2JdX45p2YOcFKWtUUs5ms3txi_FhQLwwAfUxoCkVIQAvD_BwE.

[Accessed: 15-Jan-2020]. 